\title{
Erratum to: HTA-Based Tracking of Pilot Actions in the Cockpit
}

Sebastien Mamessier and Karen M. Feigh

Erratum to:

"HTA-Based Tracking of Pilot Actions in the Cockpit" in:

R. Goonetilleke and W. Karwowski (eds.), Advances

in Physical Ergonomics and Human Factors, Advances

in Intelligent Systems and Computing 489,

DOI 10.1007/978-3-319-41694-6_10

The book was inadvertently published with a title mismatch between the manuscript and the published version. It differed in the table of contents and the chapter title. The erratum book and the chapter has been updated.

The updated original online version for this chapter can be found at DOI 10.1007/978-3-319-41694-6_10

S. Mamessier $(\bowtie) \cdot$ K.M. Feigh

School of Aerospace Engineering, Georgia Institute of Technology, Atlanta, GA 30332, USA

e-mail: sebastien.mamessier@gatech.edu

K.M. Feigh

e-mail: karen.feigh@gatech.edu 